\title{
Technical challenges of interior design solutions to address discrimination for people with special needs in designing public spaces in Egypt
}

M.D. Marwa Khaled Mahfouz, Assistant Professor, Department of Decoration - Department of Interior Architecture - Alexandria University.

Introduction:

The absence of interior design treatments for the disabled to a satisfactory extent in public spaces is one of the most important problems, especially in Egypt. As this has become something that is not universally accepted, so it became necessary to create an internal environment that is functionally appropriate and aesthetically pleasing, commensurate with the different needs of everyone with different abilities, especially in public spaces (hotels - malls - administrative buildings - clubs restaurants - Study spaces etc.) Especially since many public buildings, including the modern ones, are far from supporting the independent use of individuals with special needs .. And a large part of the problem lies in the rejection of people with disabilities, as well as healthy people, of functional designs - related. The handicapped body that ignores the aesthetic needs of the user. Where people tend to abandon the use of designs, even functionally successful, because of their lack of the aesthetic aspect of various concepts.

The "disability rights" movements began strongly in the 1960s in the USA, when the process of experiential institutional experimentation allowed people with severe physical disabilities to begin independent living. The goal of the disability rights movement was to ensure equal opportunities and eliminate social discrimination.

Bordas in 2017 explained the importance of the concept of universal accessibility - universal accessibility - which is the basis of design for disability today - and emphasized the importance of understanding accessibility as a standard for good design for all in terms of function and form, especially since it was designed with an inclusive concept. This type of design forms part of the architecture as a whole and is not just "design for the disabled".

The current design trends call for many new standards and inputs to be accommodated in the design equations for people with special needs, which is compatible at the same time with ordinary people, since the initial design concept, especially in planning and designing public spaces and designing furniture. The aim is not to design the place in a smooth and purely functional manner, but a comfortable human design that does not lack the artistic and innovative side, which avoids discrimination for a special group (people with disabilities) and helps their independent and positive social interaction, especially in public places. And interior design solutions have a big role in achieving this. 


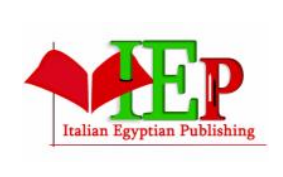

ISSN: $2735-5446$

\section{INTERNATIONAL JOURNALOF \\ MULTIDISCIPLINARY STUDIES ON MANAGEMENT, BUSINESS, AND ECONOMY}

VOLUME 3, ISSUE 1, 2020, $17-24$.

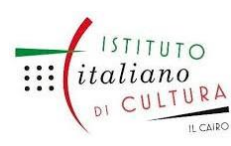

www.egyptfuture.org/ojs/

The research aims to take a new and innovative view on how disability and interior architecture are linked "aesthetically" under the name of "Desiability aesthetics." Emphasizing the criterion of "emphathy" as a primary driver in the design process and user understanding. Instead of placing disability at the end of the design process. Where you can see disability - and special needs - as starting points for the technical challenges of interior design solutions to confront discrimination for people with special needs in the design of public spaces in Egypt, creative design solutions, and the goal becomes to build a new design theory capable of increasing the overall quality and giving innovative aesthetics to design solutions. That can be accessed.

Matthew Holt discussed in 2011 the criterion of empathy, "He said: In order to clarify the aspects and consequences of the transformation to empathy-based design in its form as a user-based structure, this links it to the utopian tradition rooted in the history of design. He also presented through his research two new concepts. They are usually associated with "absorption" and "play." He renewed design based on empathy in the category of "absorption." He drew some conclusions about the social implications of this approach to design, arguing that empathy could be a design resource that could be described as "strategic".

There are already existing theories that have been developed, under various directions, which we will address, which attempt to confirm design concepts directed not only for the disabled, but for all of their differences, to counter Discrimination.

Research problem:

One of the most important problems in Egypt is the absence of adequate interior design treatments for the disabled in public spaces, and as this has become unacceptable in today's world, so it became necessary to create an interior environment that is functionally and formally appropriate to the different needs of all users of the interior space in general. Was it or private, in order to accommodate many new standards and inputs in the special design equations, intending for special needs, especially in the design of public spaces, not only to allow them to use the place in a smooth and functional way, but also in a comfortable and humane manner that does not lack the technical innovation aspect. To avoid negative discrimination and activate a positive natural reaction.

First: - Types of disabilities and the most important problems facing people with special needs in public places:

Disability is a state of disability that affects an individual who partially or completely loses the motor, sensory, or mental ability, and he may have a duplicate disability such as a motor disability with a sensory disability and so on.

1- Types of disabilities (people with special needs) people with disabilities (PWD):

People with special needs vary according to the type of their disability. The interior designer must understand their basic needs for movement and the quality of use in public interior spaces, and understand their desire for independent dealing and their refusal to discriminate from society. People can be classified according to the type of disability as follows: people with mobility disabilities (and the research will focus on them), including wheelchair users - people with visual 


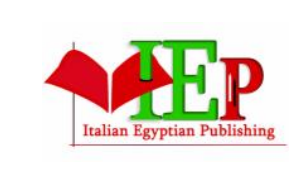

ISSN: 2735-5446

\section{INTERNATIONAL JOURNALOF \\ MULTIDISCIPLINARY STUDIES ON MANAGEMENT, BUSINESS, AND ECONOMY}

VOLUME 3, ISSUE 1, 2020, 17 - 24.

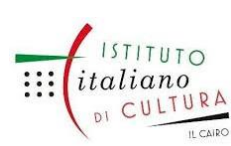

www.egyptfuture.org/ojs/

impairment - people with hearing impairment - people with mental disabilities - people with mental impairment.

Where the designer must study the types, sizes and movements of the tools and assistive technology for people with special needs that are used within the internal space (Figure 2). Examples include wheelchairs, walkers, and others. The study will focus on wheelchair users and the problems they suffer in dealing with public places.

2- The most important problems for people with special needs (mobility disability) in public spaces:

Rehabilitation of public spaces for persons with disabilities poses a design challenge for the interior architecture designer. Many public environments such as malls, restaurants, hotels and universities, etc. suffer from design errors such as not studying the availability and accessibility of people with disabilities, and other errors, which generate frustration in them, making them feel their powerlessness for the rest of society.

- And thus to distinguish it from the rest of society. The designer should aim to create environments that enable ease of use for people with different disabilities, on an equal footing, such as healthy people without drawing attention to them, which allows for the full social participation of all through public spaces, regardless of age or ability.

- The designer must also understand the basic characteristics of public spaces to study investigative planning to facilitate accessibility, and what people experience when dealing with those environments, and what this might mean in terms of issues of social construction of the space and living personal experiences. We must analyze and understand the experiences, challenges and situations that the user may go through, especially the disabled, with different disabilities and the elderly. And many field studies reveal problems, the most important of which are faced by the disabled in public places, the most important of which are:

A - poor accessibility and overall accessibility:

- And it is one of the most important problems facing people with special needs in internal public spaces. Where the concept of accessibility focuses on providing ease of access for people with disabilities, either through design solutions or through the use of assistive technology without design obstacles, and this facilitates movement within the spaces for everyone. The design should make services accessible to everyone - the disabled or others - so that "direct access" (without assistance) or "indirect access" with the help of assistive technology is easy based on the user's understanding and capabilities.

- The accessibility standard is closely related to universal design .. But often this criterion is left to the end of the design stages, not from the beginning of the project, but rather is treated as something that the engineer must achieve at some stage. This results in weak designs added and isolated from general design thinking, lacking unity with space as a whole and aesthetics. However, when accessibility requirements are considered in the initial design thought, empathy and aesthetic sense emerge to fit the details of people with special needs with the general appearance of the space, in addition to preventing the idea that they have been forgotten in the basic calculations of interior design.

B- Difficulty in recognizing wayfinding inside the place due to poor design and planning: 


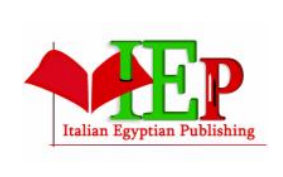

ISSN: 2735-5446

\section{INTERNATIONAL JOURNALOF \\ MULTIDISCIPLINARY STUDIES ON MANAGEMENT, BUSINESS, AND ECONOMY}

VOLUME 3, ISSUE 1, 2020, 17 - 24.

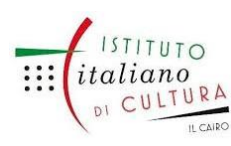

www.egyptfuture.org/ojs/

The lack of clarity of the way in the public sphere creates psychological tension in the person with special needs. Often the indicative regulations, for example, are confusing, limited and unclear. Users are not contacted by design in a comprehensive manner. Few regulations directly benefit people who suffer from mental states or cognitive impairments, and there is no need for complex devices, controls, or confusing instructions to access information and perceive services in public spheres.

Wayfinding is important to meet various needs, as road finding is a form of an integrated communication system in public spaces designed with an inclusive concept.

- The designer should study movement paths and easy ways to access services while finding innovative solutions to accommodate various users.

- This requires cooperation with graphic designers as part of the design process that should not be devoid of aesthetics and art to please the user. There are many verification methods that can be used through visual signals such as the Signage system to provide directions, maps, color and light to enhance the paths that can be designed. Creative ways.

Some people read and hear others, and others use touch. It also uses light and color to guide. Others prefer to use a combination of path design techniques. Therefore, various methods must be designed to enable the user to know the path in the general bias. And it should be incorporated into the fabric of the interior design, which in turn helps guide and may create a distinctive artistic identity within the interior space.

- Difficulty in accessing objects due to their designless dimensions: - including narrow doors for wheelchair access - high mirrors in the public bathroom - difficult access to tools in the dining buffet - limited maneuver space in bathrooms - light switches, faucets, shelves, and cabinet rails too high or low Too or too far to reach

- Door handles - controls for devices that are difficult to accommodate and operate - slippery floors narrow movement paths around sitting areas and services in public spaces etc.

Discrimination in design treatments aimed at the disabled and their lack of aesthetic aspect: design means aesthetic care. The design should include good functionality and aesthetic quality in equal proportions.

Individuals with special needs seek to use public spaces naturally with aesthetic innovation that includes measures to facilitate use in an independent manner without drawing attention to their disabilities. Lidwell defined this under the heading "Aesthetic Use Effect". The reason for this is that aesthetic designs stimulate positive emotions, but "make people more reckless to the complexity of design and more willing to give the time needed to learn how to use it."

- And the designer resorts to facilitate and provide accessibility to define secondary entrances and isolated spaces for the disabled or a back entrance for the handicapped "as an alternative to the main entrance inaccessible - a separate bathroom for the handicapped" separated from public bathrooms, as these examples can easily be judged as discriminatory. Designs are not in the concept of "design for all" but rather only designs for people with special needs and do not form part of the general thought of the interior designed environment .. Consequently, people without disabilities rarely use them, even when they are more practical, because they do not want to distinguish 


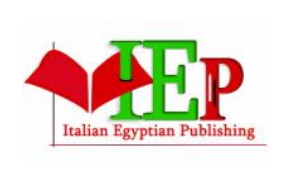

ISSN: 2735-5446

\section{INTERNATIONAL JOURNALOF \\ MULTIDISCIPLINARY STUDIES ON MANAGEMENT, BUSINESS, AND ECONOMY}

VOLUME 3, ISSUE 1, 2020, 17 - 24.

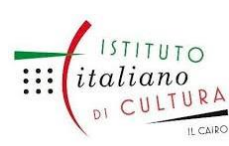

www.egyptfuture.org/ojs/

themselves with such isolated designs. People with disabilities. "Disabled designs are seen as symbols of reduced ability and thus can be easily rejected by normal human capabilities.

- On the other hand, we can find many cases in which accessibility is applied as a unified solution, and often results in the appearance of orthopedic tools, with a clear poverty of aesthetic integration with its surroundings. The aesthetic concerns of people with special needs are excluded from the design while they are considered Functional design goals such as accessibility is just a technical issue...and a missing technical aspect that will be resolved by external specialists at a later time...which is a big mistake. The result is often separate solutions that lack integration as a unit, in terms of composition and aesthetics, which is often It gets medium sweet when accessibility is just a matter of sticking the wheelchair symbol 'sticker and a few other things.

5- Planning ill-considered paths of movement, which limits the flow of movement for people with special needs.

6- The high cost of spaces designed for the disabled, but not available:

Many hotels, for example, offer "only one or two rooms equipped with easy access services", while the rest of the rooms can be usable and can be easily adapted to design according to specific standards around spaces, surfaces, edges, knobs, opening mechanisms, lighting, colors, etc. and examples worldwide. :

Silken Zentro Zaragoza (Spain): which implemented an explicit integration policy through several "polyvalent rooms". These rooms are divided properly, with soft colors, adequate lighting, and a walk-in shower equipped with a pull-out seat.

- Their clever strategy of naming the rooms has resulted in the sale of polyvalent rooms to all customers, who do not know they are in a "handicapped room", but only in a comfortable and fun place. The room rate is the normal room rate, the spaces are suitable for everyone, and are equally used, comfortable and attractive.

- Dorking Hotel Rooms in Dorking, South London puts Turkey especially on universal access .. In 2016, Sheppard Bespoke collaborated with the Royal Institute of British Architects (RIBA) in designing his goal is to promote the concept that disabled rooms should be stylish. Like those that suit ordinary guests. It should also not detract from the necessary functionality of the design. The designs are universal, personalized, flexible, functional and aesthetically pleasing.

Second: The current design theories and trends that dealt with the problem and its role in avoiding discrimination:

All new approaches, with different concepts, aim at designing for equality: the international symbol of universal access represents wheelchair users and justice among people. Interacting with the built environment, such as public places, and experiencing barriers, which mean any obstacles that prevent participation in all aspects of society and their ability to move independently, within it. This causes restrictions caused by the design's lack of awareness of holistic thinking.

The basic concept of all trends remains the same: 


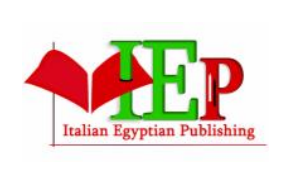

ISSN: $2735-5446$

\section{INTERNATIONAL JOURNALOF \\ MULTIDISCIPLINARY STUDIES ON MANAGEMENT, BUSINESS, AND ECONOMY}

VOLUME 3, ISSUE 1, 2020, $17-24$.

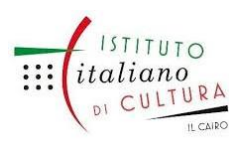

www.egyptfuture.org/ojs/

It is about DfA (Design for All), regardless of age, ability or life status, by including the needs of the largest number of consumers in different circumstances.

1- The Concept of Barrier - Free Design: It emerged all over the world in the 1960s and originated to reduce barriers for the disabled. It is considered especially for the disabled. The term "accessibility" was soon used more widely than barrier-free design, coinciding with the introduction of the International Code for Access, a mark of accessibility used around the world since the 1970s. It is also known as the "wheelchair symbol", since it is represented by a person sitting in a wheelchair painted white on blue. Elaine Ostroff explains in her 2001 book "The Comprehensive Design Guide" that the term "accessibility" replaces the initial idea of reducing barriers to The disabled, with a more specific focus on wheelchair mobility issues.

In the United States, she notes, "accessible design became more widely used than the Barrier free design in the 1970s".

2- Universal Design (UD):

It is called Design for All (DA), which means designing products, environments, programs and services that can be used by all people, to the greatest extent possible, without the need for adaptation or specialized design directed at a particular group. "The universal design does not exclude assistive devices certain groups of persons with disabilities when this is needed.

- The fact is that the standard of accessibility and accessibility is desirable for all, not only for the disabled, because the environments become easier to use, as elevators in public buildings and automatic doors, for example, are used by people with disabilities and from parents who carry prams or anyone carrying loads - Glass security barriers Along the subway platform, it is primarily considered to protect the blind and others and reduce noise levels in the station. Not surprisingly, then, the concept of barrier-free, which was initially aimed exclusively at disabled wheelchair users has evolved into a universal design idea for all (DA).

- Results:

1- A new and innovative point of view should be taken on how disability and interior architecture are related. Instead of setting - design standards for the disabled - as a technical measure - at the end of the design process, they should be considered as starting points for the creative thought of design and this may lead to the generation of an alternative type of avant-garde for the interior architecture of public spaces in Egypt.

2- Interior design supports people with disabilities in subtle ways where the design can facilitate or hinder their experiences and in turn affect their social experiences and to do this, the designer must explore how thinking, empathy, and understanding the needs of people with special needs open up the ability to creative design through interior design. The study of the emerging and important field of disability studies must be entered into, as it takes into account what different types of thinking about design solutions can offer in terms of ways to reduce the attention paid to the disabled while they use public spaces.

3- The designer must reject the design practice methods that reject creativity through functional technical solutions for the use of the disabled in order to achieve equality in a more general way. 
4- The interior design of public places - thoughtful functionally and aesthetically - gives the disabled person communication and social rapprochement and makes him feel familiarity and belonging and achieving independence, which avoids the feeling of discrimination from the healthy. - If the design thinking for the disabled fully develops to become an integral part of the general concept of interior design, awareness must be encouraged by faculty members in colleges to develop curricula that address issues of technical accessibility and academic training on them, which effectively supports and combats discrimination towards the disabled.

Bibliography:

1- Arthur \& Passini .2002 cp. 188). Arthur P. \& Passini «R. (2002). Wayfinding: People Signs and Architecture. McGraw-Hill Book.ILLUMINATION WITHIN AN INCLUSIVE ENVIRONMENT.

2- Bordas Eddy, M. (2017). Universal Accessibility: On the need of an empathy-based architecture. (Tampere University of Technology. School of Architecture. Housing Design; Vol. 26). Tampere University of Technology. Year 2017

3- Fleischer, D. and Zames, F. 2001. The disability rights movement: From charity to confrontation. Philadelphia: Temple University Press.

4- Li Wong Hong -ARCHITECTURE WITHOUT BARRIERS: Designing Inclusive Environments Accessible to All - Interior Design, Sheridan College Institute of Technology and Advanced Learning, 2006 -Bachelor of Architectural Science, Ryerson University, 2011 - (C) Hong-Li Wong 2014.

5- Groves, H. 1951. "Separate but Equal--The Doctrine of Plessy v. Ferguson". Phylon (1940-1956), vol. 12, n.1 (1st Qtr. 1951), pp.66-72. Available online at: http://www.jstor.org/stable/272323 [Last retrieved: September 2013] .

6- Holt, M. 2011. "The Limits of Empathy: Utopianism, Absorption and Theatricality in Design". In: McDonagh, D. and Thomas J. (ed.), The Design Journal, 14 (2), pp. 151-164.

7- Henry, Shawn Lawton; Abou-Zahra, Shadi; Brewer, Judy (2014). The Role of Accessibility in a Universal Web. Proceeding W4A '14 Proceedings of the 11th Web for All Conference Article No. 17. ISBN 978-14503-26513. Retrieved 2014-12-17" What is assistive technology?". washington.edu. 2018-07-02 .

8- "ISO: ISO/IEC Guide 71:2001. Guidelines for standards developers to address the needs of older persons and persons with disabilities (2001) .

9- Leontiev, EG, 'available among EYES persons with disabilities", Scientific - popular .21 (2001. Yekaterinburg, edition. 
10- Lidwell, W., Holden, K. and Butler, Lidwell, W., Holden, K. and Butler, J. 2010. Universal principles of design: 125 ways to enhance usability, influence perception, increase appeal, make better design decisions, and teach through design. Beverly, Massachusetts: Rockport Publishers. J. 2010 .

11- Lusher, R. H. \& Mace, R. L. 1989. Design for Physical and Mental Disabilities. In Encyclopedia of Architecture: Design Engineering and Construction, ed. J. Wilkes and Sons, 3.

12- Nussbaumer, L. (2012). Inclusive Design: A Universal Need (p. 31). New York: Fairchild Books.

13- Roth, L. (1993). "Commoditie": How Does the Building Function?. Understanding Architecture: Its Elements, History, and Meaning (pp. 817). New York: Icon Editions.

14- Roth, L. (1993). "Commoditie": How Does the Building Function?. Understanding Architecture: Its Elements, History, and Meaning (pp. 817). New York: Icon Editions.

15- R Mace - Universal design: housing for the lifespan of all people -R Mace - The Center for Universal Design, Nort Carolina State ..., 1988.

16- Schittich, C. (2013). Designing Circulation Areas: Stairs, Ramps, Lifts: Routing, Planning Principles. Germany: Birkhauser Architecture.

17- Steinfeld, E. \& Maisel, J. L. (2012). Universal Design: Creating Inclusive Environments. Hoboken, NJ: Wiley.

18- Wolfgang F. E. Preiser - UNIVERSAL DESIGN HANDBOOKCopyright (C) 2011, 2001 by The McGraw Hill Companies, Inc. All rights reserved. Except as permitted under the United States. ISBN: 978-007162922-5 MHID: 0-07-162922-X.

19- https://www.designindaba.com/articles/creativework/enabled-designway-finding-system-considers disabled .

20- USA: Americans with Disabilities Act, As Amended. P.L. 110-325. United States of America (2008).

21- Scandic Hotel- architects: Arkitektarna Krook \& Tjäder (interior), Narud Stokke Wiig Sivilarkitekter AS with TUPELO arkitektur (architects) .

22- http://www.inclusivedesign.no/furniture-andinterior/scandic-hotel-article 148-263.html 